might however find the 650+ pages of text tedious and hard to navigate (not to mention the $150+$ pages of scholarly apparatus). As to the translation itself, it is smooth-reading and faithful to the original, though the decision to cite the travel journal and La Boétie's Servitude volontaire in outdated English versions-Waters 1903 instead of Frame 1958, Kurz 1942 instead of Schaefer 1998 or Atkinson 2011-seems inexplicably idiosyncratic.

LAURA WILLETT

University of Toronto

\title{
Dooley, Brendan.
}

\section{Angelica's Book and the World of Reading in Late Renaissance Italy.}

London: Bloomsbury, 2016. Pp. x, $201+9$ ill. ISBN 978-1-4742-7031-1 (hardcover) US\$114.

This bibliophilic biography of one copy of a sixteenth-century collection of novellas, now obscure but popular in its time, responds well to being read in the spirit in which it was written: with a mind open to conjecture, an eye for more questions than answers, and a willingness to fuse micro- and macrohistory without concern for a few visible seams. Ambitiously inspired, it is also defensively book-ended by prefatory and concluding caveats about, and even advocacy for, its indefinite conclusions, not only in relation to this project but as they inform the humanities at their best. If Dooley admits his preference for the full half of his evidentiary glass, however, the reviewer must observe the glass as a whole. One might begin by pointing to the author's genial tone and the leisurely pace he takes in unfolding his tale of a chance junk-shop find, one concealing a tantalizing ownership inscription which almost miraculously survives in the middle of a volume shorn of numerous initial and final pages. One could then turn to his informed enthusiasm, at times contagious, for the labyrinthine sleuthing his topic engenders as he attempts to learn more about the owner, the book, and the culture they emerged from.

Dooley formulates, but generally finds he cannot firmly answer, countless questions in six chapters that range from analytical bibliography to art history as he consults evidence from Renaissance fictions and sermons to probate inventories and paintings. The author's refusal to narrow his research process 
or product to suit an instrumental agenda (which, as he notes, increasingly dominates academia) may account in part for the book's surprisingly oldfashioned, antiquarian atmosphere, as does its eccentric syncretism. Dooley sheers away from the book's obvious centre-Angelica Baldachini's (now his) copy of Straparello's Pleasant Nights-at every turn, in every direction, thus generating a kind of intellectual fireworks where the fuse that lit things is all that remains unseen. Alternatively, one could call Angelica's book, like its early modern owner, a hook on which to hang this somewhat shaggy story, told with energetic optimism about all we can learn and all we cannot (indeed, all we can learn from what we cannot). The approach is sometimes invigorating and sometimes too much about too little. One might compare it with Jill Lepore's take, in The Book of Ages, on what may be made of the meagre remains of Jane Franklin, Benjamin's sister. Lepore, like Dooley, spirals out from a minor cache of material evidence via a kind of scholarly transcendentalism not averse to imaginative power; but Lepore's poetic excurses feel more measured, and her subject's exceptional brother proves a more functional foil than the miscellany of contextualizing materials Dooley gathers around the elusive Baldachini.

If Baldachini and her book remain relatively opaque, the rationale for that opaqueness is at least made clear, and the world of reading in Renaissance Italy, the book's secondary focus, is deftly fleshed out by informed treatments of topics like the circulation of news, women's book ownership, mnemonic techniques, storytelling practices, and censorship. These treatments sometimes, however, feel indistinguishable from digressions. Dooley asks us to retrace his research path, but it is not always clear why he took certain steps along it. Why dwell on graphological manuals that claim to discern temperament from handwriting-especially since the sample is but half a dozen words? Dooley appears unironically enthused when claiming that dots on his subject's " $i$ 's" signify her love of order. Also odd is how far forward, chronologically, he will cast his net: not only consulting Renaissance graphology, in this instance, but a Victorian treatment of the same pseudoscience. Why? And why does a discussion of numerological interpretations of the figure 144-a discussion arising because the inscription is found on that page (a fact that, Dooley acknowledges, could be arbitrary) - elaborate on that number's importance to the nineteenth-century American founder of the Seventh-Day Adventists, and even D. H. Lawrence? As with most of the questions that frame many of the paragraphs in Angelica's Book, these remain unanswerable. 
Dooley's questions are answerless not for lack of effort but for lack of evidence; yet his method of recounting each dead end he met, followed by speculations on what he might have found instead, frustrates in the aggregate. Just as Angelica's book is transformed, here, into Angelica's Book, his research procedure mutates into a meta-procedure reported in the present tense, such that a dramatization of his thinking becomes the focus: he frames a question; finds he cannot answer it; reports that fact; conjures some possible answers; and, finally, reminds us that he is speculating. Negative results deserve publication in the humanities as in the sciences, but it is more efficient, from a reader's view, for an author to corral these apart from his positive findings. Dooley's defense of his more dilatory method is to suggest that the journey bests the destination, but that cliché is truest for travellers themselves; as readers, we are more like those subjected to a peripatetic friend's slideshow of photographs, narrated by their maker one by one, in the order taken, no matter how trivial or blurred. Editing is in everyone's best interest.

However much I wanted more from this book-possibly by having less of some of its methodological quirks - that feeling perhaps appropriately echoes its author's motivation in writing it. I respect his humble characterization of the book as an "interim version" (134) of the fuller history he hopes it will eventually join, as well as his experimental embrace of serendipity, inference, open questions, and conjecture as crucial elements in humanistic research at a time when merely admitting their existence, let alone working constructively with them, seems risky. Angelica's book survives, perhaps like all books, in an imperfect state; we should not demand the impossible of Angelica's Book, especially since the unanswered questions are what let our work go on.

LEAH KNIGHT

Brock University 